\title{
Perspectives on quality and content of information for juvenile idiopathic arthritis on Italian Web pages: a different way to meet the needs of families?
}

\author{
P. S. Buonuomo $\cdot$ O. Adorisio
}

Received: 14 June 2011/ Accepted: 22 October 2011/Published online: 8 November 2011

(C) Springer-Verlag 2011

Dear Editor,

The interest on quality and content of information for parents is growing over time [1], especially for patients with chronic disease and special needs [2]. Differences seem to be relevant in different geographical settings [3].

With the aim to determine the quality and content of Italian language Internet information about juvenile idiopathic arthritis (JIA) (in Italian Artrite Idiopatica Giovanile, AIG) from the perspectives of consumers and health care professionals and reproducing a previous study [4], we conducted a specific search.

Key words relevant to AIG were searched across 10 search engines (Google, Yahoo, Excite, Altavista, hippy.com, AOL search, Ask.com, Hotbot, Lycos, Bing). The first 50 results were included in the study. Forum, commercial and social network pages were excluded. Quality of information was appraised independently by two health professionals and then offered to the evaluation of two parents using the DISCERN tool. Concordance of the website content (i.e. accuracy and completeness) with available evidence about the management of AIG was determined. Readability was determined using FleschKincaid grade level and Reading Ease Score. Of the 500 Web pages accessed, 211 unique sites (42\%) met the inclusion criteria; 78 sites (37\%) are related to health care institutions.

\section{P. S. Buonuomo ( $₫)$}

Department of Pediatric Medicine, Rheumatology Unit,

Bambino Gesù Children's Hospital, Rome, Italy

e-mail: sabrina.buonuomo@gmail.com

O. Adorisio

Department of Pediatric Surgery and Transplantation Center,

Bambino Gesù Children's Hospital, Rome, Italy
The overall quality of website information was generally good with a mean DISCERN quality rating score of 67.92 of 75 (range 50.0-70.5). Overall completeness of sites was 12 of 16 (range 9.25-14.25), and accuracy was 2.9 of 4 (range 2-4), indicating a moderate level of accuracy. The best level of information regards medical treatment, especially biological agents.

In contrast to previous observations [4] regarding websites in English language, Italian websites seem to have higher quality at an appropriate reading level for parents of children with AIG. This may be due to the fact that a significant portion of the most Italian websites on JIA (AIG) is related to health care institutions.

\section{References}

1. Damman OC, Hendriks M, Rademakers J et al (2009) How do healthcare consumers process and evaluate comparative healthcare information? A qualitative study using cognitive interviews. BMC Public Health 20(9):423

2. Lopez-Jornet P, Camacho-Alonso F (2010) The quality of patientorientated Internet information on oral lichen planus: a pilot study. J Eval Clin Pract 16(5):883-886

3. Tozzi AE, Buonuomo PS, Ciofi degli Atti ML et al (2010) Comparison of quality of internet pages on human papillomavirus immunization in Italian and in English. J Adolesc Health 46(1): $83-89$

4. Stinson JN, Tucker L, Huber A et al (2009) Surfing for juvenile idiopathic arthritis: perspectives on quality and content of information on the internet. J Rheumatol 36(8):1755-1762 